\title{
Contribuições de metodologias de Design para a prática pedagógica: apresentação de um esquema inicial
}

\section{Contributions of design methodologies towards pedagogical practice: presentation of an initial schema}

\author{
Maria Teresa Lopes, Solange Galvão Coutinho, Natália Cristina Pereira Barbosa
}

metodologias de design, design da informação

\begin{abstract}
Este artigo expõe o resultado de uma investigação que objetivou apresentar um esquema inicial de contribuições de metodologias de Design para a prática pedagógica, cujo foco incide na formação de não especialista em design. Entrevistas com estudantes e docentes das licenciaturas do estado de Pernambuco foram conduzidas com o intuito de compreender o grau de aproximação do professor com os conteúdos de design. Para tal foi utilizado um questionário do tipo snowball combinado com o método de análise de imagens paradas de Gemma Penn (2008). Em seguida, fundamentos e metodologias do Design da Informação foram revisitados de forma a subsidiar a estrutura teórica. A interseção das respostas dos entrevistados com o aporte teórico possibilitou a construção uma metodologia preliminar a ser adotada pelos docentes para a produção de artefatos educacionais.
\end{abstract}

design methodologies, information design

This paper discusses the results of an investigation, the aim of which was to present an initial schema of design methodologies towards pedagogical practice, focusing on teacher training courses for non-specialists in the area of design. Interviews were conducted with students and teachers on training courses in the state of Pernambuco (Brazil), in order to obtain a better understanding of the degree with which they approach design contents. For this, a snowball survey was conducted combined with methods of still image analysis by Gemma Penn (2008). Following this, the rationale and methodologies of Information Design were reviewed in order to provide support for the theoretical structure. The intersection of the participant responses along with the theoretical source enabled the construction of a preliminary methodology to be adopted by teachers when producing educational artifacts.

\section{Introdução}

Este trabalho apresenta alguns resultados da investigação intitulada Metodologia de design e a prática pedagógica na sala de aula: a construção inicial de uma Matriz de Metodologias Contributivas, o qual se ancora no projeto de pesquisa Ensina Design cuja finalidade consiste em propor conteúdos de design da informação, relacionados ao uso da linguagem gráfica (verbalnumérica, pictórica e esquemática) no ensino fundamental brasileiro (figura 1).

Figura 1: Gráfico das áreas de desenvolvimento da pesquisa

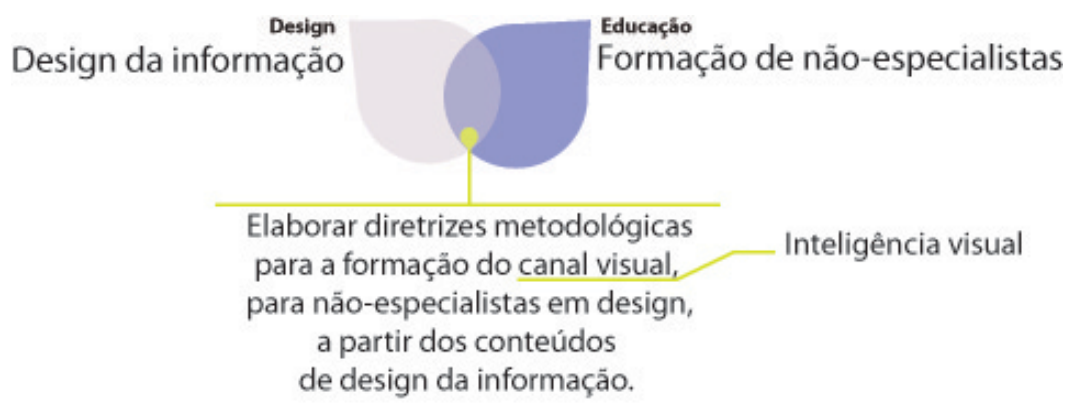

InfoDesign | Revista Brasileira de Design da Informação / Brazilian Journal of Information Design São Paulo | v. 9 | n. 1 [2012], p. 10 - 20 | ISSN 1808-5377 
Para tanto apresenta dois polos de discussão: o primeiro expõe resumidamente a fase de aproximação com os professores, que compreende um questionário (survey) combinado com o método de análise de imagens paradas de Gemma Penn, com a finalidade de obter dados por meio da análise do discurso dos professores; o segundo faz referência à fase epistemológica inicial, no âmbito dos conteúdos de design da informação para a construção de uma Matriz de Metodologias Contributivas (MMC), de forma a subsidiar propostas que visem a articular o design como um conteúdo formador de não especialistas.

\section{Mapeamento da relação do professor com os conteúdos de design}

Para se estabelecer uma relação de sinergia com os professores foi elaborado um questionário do tipo snowball combinado com o método de análise de imagens paradas de Gemma Penn (2008), no intuito de compreender qual o grau de aproximação do professor com os conteúdos de design. Se ele observa o design fazendo parte da sua vida, por meios dos artefatos didáticos com que trabalha ou se ele entende o design como um conhecimento que pode ser incorporado ao seu campo de trabalho.

As entrevistas foram realizadas de maio a julho de 2012, registradas por meio audiovisual, conduzidas individualmente com 33 estudantes e professores das licenciaturas do estado de Pernambuco (Recife e Caruaru). O grupo de participantes selecionados obedeceu ao critério de estarem atuando em sala de aula, ter cursado ou estar cursando uma das licenciaturas ou mesmo o curso de pedagogia, sendo sete estudantes e 26 professores entre 18 e 50 anos.

O questionário foi composto por quatro perguntas, onde em uma delas eram mostradas sete imagens. Essas imagens ${ }^{1}$ representavam os artefatos didáticos que geralmente estão presentes no cotidiano do professor e, que tem relação com o design gráfico e da informação, tanto nos seus aspectos visuais, quanto organizacionais.

As perguntas seguem descritas abaixo:

1. Como você entende o significado dessa palavra? (na cartela: "DESIGN GRÁFICO");

2. A partir do significado que você dá a palavra "design" como você entende essas imagens? (foram apresentadas as sete imagens);

3. Como você vê a relação do design com a escola?

4. Você tem interesse em fazer um curso de formação em conteúdos de design para professores?

Decidimos fazer uso do método de pesquisa do tipo survey, pois o mesmo se propõe a obter dados ou informações sobre opiniões de um determinado grupo de pessoas, em um nível superficial de conhecimento. Este método nos possibilitou responder questões do tipo "o que?", "por quê?", "como?" e "quanto?". No caso estudado, o interesse foi em entender como se dá a relação do professor com o design, em um nível de familiaridade e abstração - ou "como e por que isso está acontecendo" - neste caso, foi importante também analisar se o participante entenderia que a relação entre ele e o design já seria algo existente.

\subsection{Método combinado de análise: imagens paradas de Gemma Penn}

O modelo de análise elaborado por Gemma Penn (2008) se preocupa em investigar a relação de como as pessoas produzem a construção de significado a partir de imagens e, foi utilizado por meio do uso das imagens fotográficas, demonstradas durante as entrevistas realizadas. Este método se fez necessário, por dois motivos: o primeiro, entender a relação do professor com os artefatos, consequentemente com o design e, o segundo, na realização de mapeamentos de como o professor constrói os significados a partir de uma mensagem visual.

\section{Transcrição e análise das entrevistas}

Nesta etapa, primeiramente, três entrevistas foram escolhidas, cujo recorte se deu por representarem os graus de envolvimento com o design, ou seja, alto, médio e muito baixo. Elas foram estudadas com a finalidade de fornecer uma base para a análise geral, que foi conduzida

\footnotetext{
${ }^{1}$ As imagens foram as seguintes: (1) Lousa branca e pincel atômico; (2) Quadro verde e giz; (3) Lousa digital; (4) Livros Didáticos; (5) Tablet; (6) Computador com datashow e, (7) Computador com a interface do facebook.
} 
posteriormente. Nesta análise, todos os vídeos das entrevistas foram revistos de forma a buscar as principais ideias expressas, em relação a cada imagem que foi apresentada e, comparada com as anotações feitas durante o momento da entrevista.

Ademais, foram escolhidos momentos das entrevistas que sintetizam a visão geral dos participantes referente ao assunto discutido. Esses momentos foram transcritos e discutidos e serão apresentados mais a adiante ${ }^{2}$.

\subsection{Apresentação da análise geral por perguntas}

A análise apresentada a seguir é consequência do survey explicado em item anterior e está apoiada na fala dos professores entrevistados durante o período de maio a julho de 2012. Devido ao grande número de falas analisadas, as que aqui estão expostas são recortes que sintetizam o que o grupo de participantes apresentou como consideração para cada imagem apresentada nesta etapa do experimento. Entretanto, destacamos que o texto analítico que as acompanha é um resumo de todas as falas dos 33 participantes.

\section{Cartela 1: O significado do termo Design Gráfico (1ª pergunta)}

"Design gráfico é você expressar alguma coisa através do desenho. Expressar o...., um objeto, alguma coisa através do desenho" (P_04_PD).

Essa resposta expressa o pensamento de alguns participantes dentro do nosso grupo de entrevistados. Onde a maioria associa o termo "design gráfico" a palavra 'desenho'. Nesse grupo alguns fizeram a relação de "design gráfico" com o termo 'desenho gráfico', porém, por não haver mais explicações das próprias professoras sobre o assunto não ficou claro de que forma elas entendiam o seu significado.

\section{Cartela $2^{3}$ : A relação do design gráfico com o quadro branco e piloto}

"Eu imagino que seja assim a maneira de dispor os conteúdos, no intuito de chamar mais atenção no nosso caso do nosso cliente, que é o aluno" (P_01_SNF).

O quadro branco é conhecido pelos professores como uma ferramenta para a apresentação dos conteúdos escolares e, a grande maioria dos entrevistados observa o design gráfico inserido nessa ferramenta por meio da organização das informações, de modo a facilitar a compreensão de determinado assunto pela turma. Eles entendem que deveria haver um propósito na maneira como a informação é colocada para o aluno e também se incomodam quando não há uma boa organização das ideias expostas no quadro.

\section{Cartela 3: A relação do design gráfico com o quadro verde e giz}

"É como se você ficasse preso no tempo com o quadro verde e giz e no quadro branco não, você solta mais as ideias é como se corresse mais as ideias" (P_01_UFPE).

Esta fala demonstra o pensamento de que a utilização do quadro verde é algo que, para eles, ficou no passado como um método mais tradicional de dar aula, que muitas vezes não é o melhor. Alguns professores consideravam sua utilização tão ultrapassada que não viam como uma área do conhecimento atual como o design poderia ser relacionada com o artefato.

\section{Cartela 4: A relação do design gráfico com a lousa digital}

"Então, assim, para transmissão do conteúdo é bem mais prático. O tempo, nós ganhamos mais tempo porque você não tem o trabalho de copiar no quadro, enfim. $E$ com um detalhe importante, né? Já estamos destacando a questão do design, é digital é... é mais perfeito! Aí o gráfico realmente é mais perfeito, você pode entrar em outros recursos e transmitir pra cá, entrar com outras fontes, enfim." (P_02_BC)

Compreende-se o pensamento da maioria dos docentes entrevistados. Os professores tendem a enxergar a lousa digital como uma evolução tecnológica em relação ao quadro branco, como um instrumento possuidor de mais recursos que atuam tanto para facilitar o dia-a-dia do professor em

\footnotetext{
${ }^{2}$ Para uma melhor compreensão, esclarecemos os códigos atribuídos neste artigo quanto ao tipo de legenda adotada para as unidades de análise: As falas das entrevistas que serão apresentadas possuem uma referencia quanto ao participante entrevistado que a emitiu, segue um exemplo: (Fala 05_P_02_BC) > Onde Fala 05 corresponde ao quinto tópico frasal do "P" de Professor, "02" indica a sequencia que a entrevista foi feita em um determinado local, no caso, esta foi a segunda entrevista realizada no "BC" que se refere às iniciais do colégio ou instituição de ensino em questão. ${ }^{3}$ Os comentários e considerações dos tópicos da cartela 2 a 8 (referentes as imagens) são conectadas a resposta da $2^{a}$ pergunta: A partir do significado que você dá a palavra "design" como você entende essas imagens?
} 
sala de aula, ou ainda, como algo que gera uma maior interatividade do aluno com o conteúdo que é transmitido. É interessante observar que mesmo muitos dos professores não possuindo um contato direto com a lousa digital eles tem uma ideia positiva do artefato.

\section{Cartela 5: a relação do design gráfico com o livro didático}

"Eu acho que a forma como as coisas são compostas a forma como elas são dispostas no livro é muito importante para compor o entendimento do estudante" (P_06_UFPE).

Nenhum participante descartou o uso do livro didático, pelo contrario todos demonstraram ver o livro como uma ferramenta de suporte muito importante para o professor. Contudo, há um entendimento comum de que o livro não pode ser o único artefato de ensino a ser trabalhado em sala de aula. Quanto ao design gráfico, os professores mencionam vê-lo inserido no livro didático por meio da organização de texto e imagens, da preocupação no uso das cores, na escolha do formato das letras, numa capa com uma estética diferente e mais que isso eles entendem que um bom trabalho do profissional de design gráfico é importante para que o aluno venha a se interessar e apreciar o livro.

\section{Cartela 6: a relação do design gráfico com o tablet}

"As ferramentas que tem no tablet, as questões de... eu num entendo muito bem de software, mas é tudo pensado, organizado, colocado em cada lugar pra facilitar mesmo que depois o usuário possa modificar, mas tem um lugarzinho eu acho pra cada item" (P_05_UFPE).

De uma maneira geral os professores enxergam o tablet como uma evolução dos artefatos didáticos, principalmente por esse produto ter uma profunda relação com a tecnologia e por ser, dentre os artefatos apresentados, o de produção mais recente. Do mesmo modo que a acontece com a lousa digital, o tablet é visto pelos docentes como um instrumento facilitador do trabalho do professor que é ainda mais prático do que a lousa, pois há uma maior facilidade no seu transporte e manuseio. Os professores não veem esse artefato como um possível substituto do livro didático, eles o veem como outro recurso para ser utilizado nas escolas que poder vir até a auxiliar o uso do livro didático.

\section{Cartela 7: a relação do design gráfico com o datashow}

“... por exemplo, essa abelhinha aqui... deve ser aula de ciências, né? Eles são bem pequenos. Acho que a professora tá mostrando a anatomia da abelha e aí tem assim uma abelhinha bem bonitinha então eu acho que o design ajuda muito nisso porque a gente sabe que uma aula fica bem mais dinâmica e isso não é superficial, sabe? A gente sabe que esse dinamismo numa aula retém mais a atenção do aluno e óbvio facilita o aprendizado, né? Acho que é essa a relação com o design" (P_04_UFPE).

O datashow é um artefato que está mais presente na sala de aula, já se tornando, segundo comentários de alguns entrevistados, um instrumento indispensável. Para os professores ele segue a mesma linha da lousa e do tablet, por também ser uma tecnologia relativamente nova dentro da escola, por possibilitar uma forma de ensino diferente e por gerar um grau de interação muito maior do aluno com o conhecimento que é transmitido para ele.

\section{Cartela 8: A relação do design gráfico das redes sociais com a interface do facebook}

"Bom, nas redes sociais eu acho que o design já é proposital pra conduzir as pessoas a fazer determinadas coisas... Então a distribuição das ferramentas nas redes sociais já vai estimulando você a tornar a fazer alguma coisa, assim pra usar, né? Se não num tinha necessidade, você fazia uma coisa escondida, num tinha a necessidade de tá ali, né?" (P_01_UFPE).

Observa-se um pensamento comum dos professores entrevistados que entendem que, há um projeto por trás da interface do facebook, pensado para garantir uma maior interação do usuário com as ferramentas presentes nessa rede social. Eles dizem ver o design gráfico presente na forma como se dispõe e se agrupam os ícones, as mensagens, as propagandas, ou seja, na maneira em que são organizados os elementos que compõem a página em geral. 


\section{$3^{a}$ pergunta: sobre a relação do design com a escola}

"Eu acho que o design tá muito envolvido com o aluno gostar da escola, porque quando você entra num ambiente que ele é bem trabalhado nesse aspecto, ele se familiariza... e dentro da sala de aula, o que me chamou atenção a isso é a questão da memória visual, porque um esquema bem feito, uma imagem bem sequenciada é perfeita pra você estudar" (P_02_UFPE).

Em geral, os professores entrevistados percebem que existe uma relação do design com a escola e, que ela é determinante no aprendizado do aluno, mas que nem sempre é bem trabalhada. Às vezes, essa relação é mais explicita para uns professores do que para outros, mas há uma reivindicação comum entre eles quanto a pouca ou a falta de capacitação dada a fim de auxiliar o docente, no uso dos artefatos mais recentes que oferecem grandes possibilidades de trabalhar a linguagem visual.

$4^{a}$ pergunta: sobre o interesse dos professores de participar de um curso de formação em conteúdos de design

"Olha de certa forma sim porque eu acho que tudo que vem a enriquecer a nós mesmo como profissionais e ao nosso trabalho pra comunidade, assim, eu teria, mas eu não disponho de tempo. Porque eu saio de uma escola pra outra e só tenho a noite pra fazer coisas e descansar um pouco aí fica difícil" (P_05_PD).

Os professores se mostraram interessados em fazer o curso proposto, mas existe um empecilho colocado pelos entrevistados, como demonstra a fala acima, que é a questão do tempo. Muitos dos docentes trabalham em dois ou em três turnos por dia e, acabam não possuindo muita disponibilidade para realizar outras atividades.

\section{A formação dos professores com base nos argumentos do design da informação}

Para entender melhor o conceito das metodologias de design temos a definição de Roozenburg citado por Demarchi \& Rego que afirma:

A metodologia de design dá ao designer maiores conhecimentos sobre o processo de design, como a compreensão dos modelos de design, representando a ação em projetar e a estrutura de pensar, além de oferecer métodos e técnicas que possam ser utilizadas no processo, concepção e terminologias correspondentes. A metodologia de design também oferece regras a serem usadas para projetar, "ensinando" o projetista como agir em determinadas situações. As metodologias de design servem, assim, de suporte para a organização de um processo de criação, dando auxilio através de métodos e técnicas.

(Roozenburg, 1996 apud Demarchi \& Rego, 2002:28)

Com os professores das licenciaturas as metodologias devem funcionar com o mesmo propósito, oferecendo-os o apoio necessário no processo de geração dos artefatos escolares. Como não existe ainda um procedimento que seja voltado especificamente para o educador, a finalidade desta primeira fase do projeto se deu na criação de uma metodologia que pudesse ajustar-se à qualquer artefato didático que o professor quisesse gerar e que também fosse simples ao entendimento dele. Para tal, revisitamos algumas metodologias advindas do design da informação, como subsídio para gerar a metodologia preliminar, descritas nos subtópicos a seguir.

\subsection{Estudo de metodologias contributivas com foco no design da informação}

Por trabalhar com a comunicação informacional, o design da informação apresenta vários elementos que podem ser desenvolvidos, junto aos professores das licenciaturas, para aprimorar a qualidade das informações visuais que são transmitidas por eles para os alunos. Acerca deste tema Coutinho \& Freire ponderam:

Investigações que abordem estudos nesse campo de sombreamento (no sentindo positivo) poderão beneficiar de maneira significativa a qualidade do ensino através da visão sistemática, organizacional e prospectiva própria da atividade do design da informação. (...) Atribuições essas que possibilitam diagnosticar e identificar problemas, avaliar e analisar situações de uso, e propor a otimização dos sistemas informacionais (instrucionais, comunicacionais, hierárquicos, estruturais, entre outros) dos produtos educacionais (...). (Coutinho \& Freire, 2007:245)

As características atribuídas nesse trecho ao design da informação se apoiam em um objetivo comum: melhorar a forma como o usuário/publico alvo adquire informação dos sistemas comunicacionais. Desse modo torna-se claro que para desenvolver artefatos que transmitam a 
informação de maneira eficiente é necessário, primeiramente, entender o público com o qual se vai trabalhar.

\section{Estudo do público alvo: como o público alvo reage/absorve a informação}

Segundo Schriver (1997) existem algumas questões básicas que devem ser observadas ao lidar com um público alvo. Tais questões foram examinadas com o objetivo de demonstrar como encaixam-se ao universo da educação, onde o professor atua como mediador do conhecimento. São elas:

\section{(1) Ter certeza de que o público entende o que está sendo dito/escrito:}

Para tal torna-se necessário compreender se o que está na página ficou claro, assim como tentar perceber quais as informações que não foram representadas. De acordo com Dondis (1997), a compreensão do significado de uma mensagem visual pode ser determinada pelos aspectos que a representam, como a cor, o tamanho, a proporção, entre outros. Assim a utilização ou omissão de detalhes desnecessários, traços que tornam as formas visuais ambíguas, deveriam ser evitados. No caso do professor, é importante que ele esteja atento ao repertório imagético daquela criança/adolescente, que saiba o que ela é capaz de reconhecer e assimilar, para que os recursos visuais utilizados não causem confusão na hora das atividades escolares.

(2) Ter certeza que o público entende a linguagem gráfica do artefato:

Estudos demonstram que a familiaridade do leitor com a informação gráfica é um aspecto fundamental na compreensão da mensagem, principalmente quando direcionada para um público com pouca ou nenhuma experiência com a comunicação pictórica (Goldsmith, 1984). O professor deveria poder reconhecer os erros gráficos que dificultam, por exemplo, a leitura de uma mensagem, a compreensão de uma imagem pelo aluno, entre outros.

(3) Saber trabalhar a parte escrita com a parte gráfica juntas de forma integrada:

Acerca da produção de livros didáticos Coutinho \& Freire afirmam:

(...) "Durante um longo período, o esforço na produção do livro se restringiu ao texto escrito e ao seu conteúdo, as imagens desempenhavam um papel secundário ou decorativo. Hoje, porém, percebe-se uma mudança, a imagem começa a assumir um papel menos decorativo e mais ilustrativo, no sentindo de apoiar e complementar o conteúdo textual" (...) (Coutinho \& Freire, 2007:250)

A relação imagética e textual precisa ser trabalhada de forma a contribuir objetivamente para o desenvolvimento da capacidade de observação e leitura visual dos jovens. Principalmente em relação às crianças, sabe-se que os livros ilustrados despertam um interesse maior e facilitam a percepção e apreensão do conteúdo.

(4) Saber da importância das emoções, sentimentos e motivações assim como do processo cognitivo do público/leitor:

Iniciamos a discussão deste item com os argumentos de Pine \& Gilmore:

As mudanças pelas quais a sociedade passou ao longo do século XX levaram a alterações na forma como consumidores e usuários tomam suas decisões de consumo. Saímos de uma economia essencialmente agrícola para uma economia experiencial, ou seja, o que está em oferta agora não é apenas o produto, mas a experiência causada pela sua compra. Distinta da oferta de serviços, a oferta de experiências é caracterizada pelo envolvimento do consumidor na vivência de uma situação memorável. O cenário do serviço seria o palco onde essa experiência ocorre. (Pine \& Gilmore, 1998:33)

Desse modo, entender o que motiva o consumidor a desejar, quais os seus valores, como se envolver na vivencia de experiências, aspirações passa a ser demasiadamente importante para o sucesso do artefato. É importante que os professores trabalhem essas questões com os seus alunos, visto que conhecer o público para quem se trabalha é essencial para a aceitação do projeto. Saber, por exemplo, o que o atrai, o que funciona até mesmo o que causa estranhamento e não identificação.

Aliado as questões apontadas por Schriver (1997), apresentamos resumidamente, na figura 2, alguns apontamentos advindos do campo do design da informação de Redish (2000), Sless (2005) e Simlinger (2007), que constituem a construção inicial de uma Matriz de Metodologia Contributivas (MMC). A matriz organiza a base da metodologia preliminar destinada à produção de artefatos escolares, exposta do subtópico seguinte. 
Figura 2: Matriz de Metodologias Contributivas (MMC) aplicada ao design da informação ${ }^{4}$

Redish: plano de informação

1. Quais seus objetivos? 2. Quem vai usar? 3. Como vão usar?

4. Onde vão usar? 5. Que informação eles precisam?

Sless: indentificar contexto, definir requisitos, analisar erros passados.

Simlinger: Se familiarizar com a informação, e com o ambiente onde ela será passada, estudar o usuário, definir objetivos.

Redish: coletar informação, selecionar e organizar o conteúdo da informação, preparar a estrutura onde o conteúdo irá ficar, fazer o layout, produção estética.

Sless: realizar o projeto usando gráficos, tipografia, layout, cores, linguagem e estrutura apropriados.

Simlinger: compor a informação utilizando elementos verbais, pictóricos, acústicos, haptics e/ou olfativos.

Redish: revisar, complementar, produzir e lançar.

Sless: testar, análisar, diagnosticar, redefinir e produzir.

Simlinger: avaliar, refinar, mudar e produzir.
Fase 1 - Análise do contexto: perguntas e mapeamentos.
Fase 2 -

Desenvolvimento:

coleta e

estruturação.
Fase 3 - Avaliação:

teste, reformulação e produção.

\subsection{Metodologia preliminar destinada a produção dos artefatos escolares}

Este subtópico apresenta o resultado desta investigação e descreve a metodologia preliminar proposta.

\section{Fase 1 | Análise do contexto}

Perguntas: Aqui o professor pode começar se fazendo perguntas simples, tendo o seu aluno como foco de questões, como: (1) Quais os meus objetivos com este artefato? (2) Quem vai usar esse artefato que quero gerar? Definir o usuário e estudá-lo através de métodos apropriados como observação e entrevistas; (3) Como os meus alunos vão usar este artefato? (4) Onde os meus alunos irão usar este artefato? (5) Quais as informações que os meus alunos precisam obter deste artefato? Essas perguntas vão fornecer respostas que guiará o professor no processo de construção do artefato gráfico escolar.

\footnotetext{
${ }^{4} \mathrm{O}$ infográfico teve como suporte os argumentos de Freitas (2011).
} 


\section{Mapeamentos:}

- Mapeamento da base do problema: Depois deverão ser recolhidas informações acerca do problema em questão. É muito importante reconhecer o problema e entender o significado que o artefato terá no ambiente escolar, isso permite uma melhor compreensão do propósito educacional e da informação que por ele é passada. Essa também é a fase onde o professor deve especificar seus objetivos e definir os requisitos de desempenho que ele espera que artefato escolar alcance.

- Mapeamento de similares: São diagnosticados e analisados erros e acertos passados (análise de similares) a fim de descobrir como o artefato existente e a informação passada por ele estão funcionando em relação aos requisitos de desempenho definidos anteriormente.

- Mapeamento tecnológico: O artefato escolar que será gerado precisará de determinadas tecnologias para a sua construção. O professor deve estar ciente de quais tecnologias deverão ser utilizadas, apresentando a habilidade necessária para usá-las.

\section{Fase 2 | Desenvolvimento}

Fase para gerar soluções. Para o professor é importante exercitar a criatividade, não ficando restrito a um só modelo de artefato, mas experimentando várias formas para que se chegue a melhor solução possível. Experimentar várias maneiras, por exemplo, de se organizar um mural, um cartaz, slides e ver qual delas atende melhor as necessidades dos alunos.

Coleta de informação: Nessa fase o professor deve começar a coletar as informações que quer passar aos seus alunos.

Estrutura da hierarquia da informação: Aqui as informações devem ser selecionadas e organizadas, trabalhando assim a hierarquia das mesmas. Por trabalhar a hierarquia entende-se que o professor deve perceber o grau de importância de cada informação presente, qual delas merece maior destaque e quais podem ser trabalhadas num segundo plano.

Estrutura estética do artefato: É necessário preparar a estrutura onde essas informações serão dispostas, gerando primeiramente esboços para depois produzir esteticamente o artefato. Para isso professor deve ter uma formação que o faça se sentir familiarizado com os fundamentos da linguagem gráfica (forma, cor, textura, tipografia, imagem), pois dessa forma ele poderá apresentar as informações com um nível superior as já existentes.

\section{Fase 3 | Avaliação}

Aqui as alternativas criadas como possíveis soluções do referido problema de design da informação escolar são avaliadas e a mais adequada ao problema escolhida, podendo haver uma reformulação ou não do artefato.

Teste: $\mathrm{O}$ professor deve testar analisar e diagnosticar como o artefato está funcionando em relação aos requisitos de desempenho, para perceber se ele está realmente alcançando as expectativas.

Reformulação: Se o artefato não estiver alcançando os resultados esperados, novas avaliações deverão ser feitas para aperfeiçoa-lo considerando alternativas ou identificando obstáculos que podem ser superados com uma mudança de direção. Também é necessário revisar a eficiência da informação que ele está procurando transmitir e se preciso completá-las.

Essa metodologia ambiciona trabalhar com todos os aspectos que se fazem presentes na criação do material gráfico escolar, porém sua eficácia só será confirmada depois que este processo de métodos e técnicas for posto em prática pelos professores, dentro do ambiente escolar, a seguir apresentamos de forma esquemática a metodologia preliminar desenvolvida (figura 3). 
Figura 3: Gráfico resumo da metodologia preliminar proposta

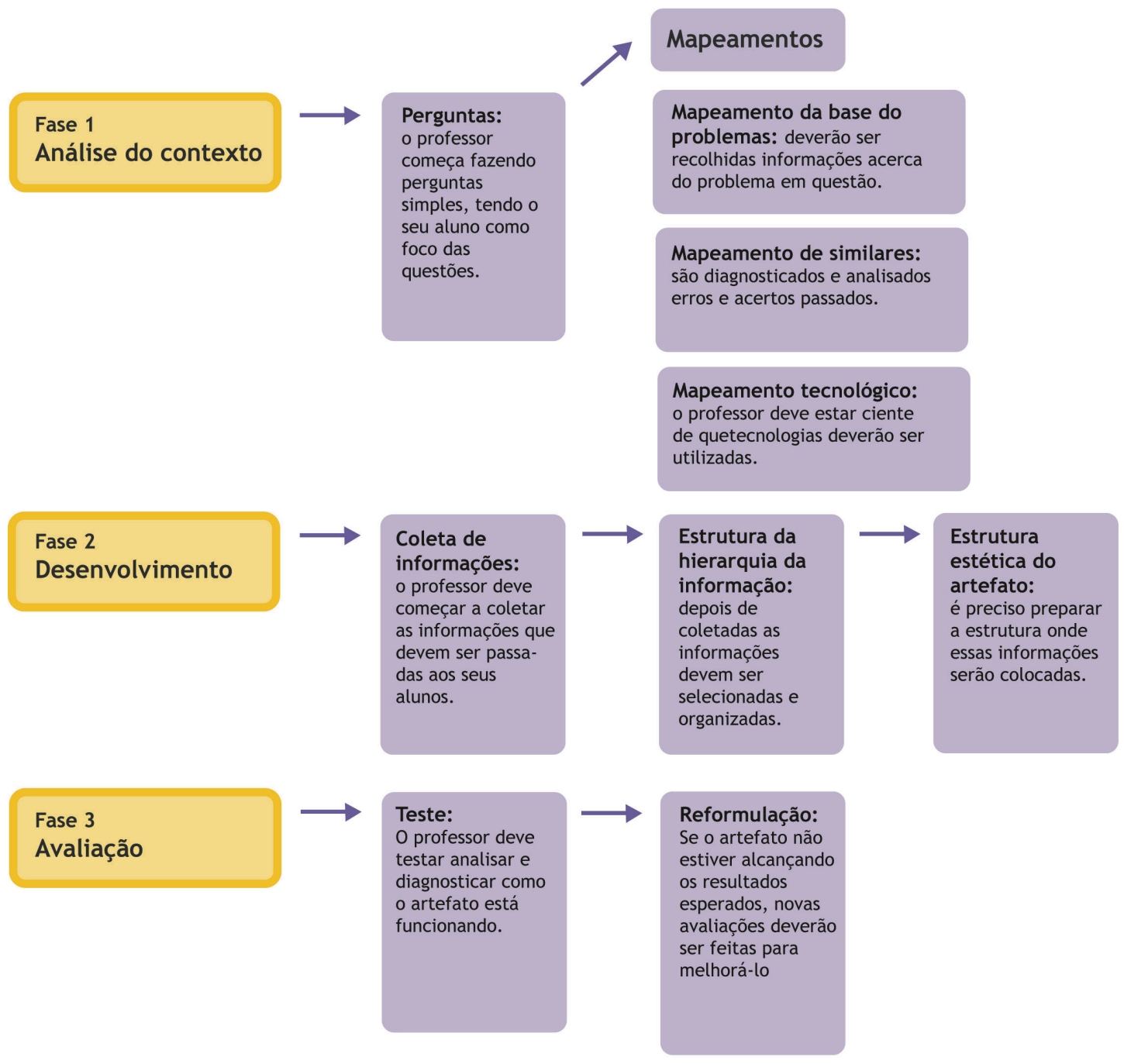

\section{Considerações Finais}

Concluímos este artigo reforçando a necessidade de ampliar e fortalecer as pesquisas que articulam processos interventivos de design, no caso aqui tratado os de base educacional e formadora, que se estabelece junto aos não especialistas na área.

Entendendo que a aproximação do professor com os conteúdos de design ainda é frágil, uma vez que, a partir da análise do seu discurso, se pode perceber que design não é necessariamente um conteúdo que está associado a sua prática social.

Ao mesmo tempo é identificado como 'algo' de extrema relevância, visto que muitos expressam o seu interesse em fazer uma aproximação entre os seus conteúdos, ou seja, o que eles produzem como artefatos escolares. Tal constatação reforça o que já se pode comprovar em pesquisas anteriormente realizadas pelo Ensina Design.

Outro aspecto importante refere-se ao encantamento pelos artefatos educacionais de natureza tecnológica, como o tablet e a lousa digital, mesmo não experienciados pela maioria dos entrevistados. O que nos inquieta, é que a geração de material educativo de natureza não digital (lousa, fichas de aulas, murais, etc.) ainda encontra-se em estado bruto, no que concerne ao uso da linguagem gráfica, como apontam (Coutinho, 2011; Coutinho \& Lopes 2011). Este fato pode acarretar em novos tipos de problemas, para além do uso da tecnologia, ou seja, a transposição 
de uma prática já consolidada de uso restrito da linguagem gráfica, para os novos artefatos de natureza digital.

O que propomos é uma intervenção urgente, que se configura como um rumo epistemológico para a proposição de diretrizes andragógicas, cujo design da informação se estabelece como um argumento metodológico que interage entre as diversas outras metodologias de design e circula nas fronteiras do design e da educação.

\section{Agradecimento}

A todos os participantes e instituições os quais não seria possível à execução desta investigação, cujo financiamento teve o apoio da Pró-Reitoria de Pesquisa da UFPE e do CNPq.

\section{Referências}

COUTINHO, S. G. 2011. Ensina Design: A introdução de conteúdos de Design Gráfico no currículo do Ensino Fundamental Brasileiro. Relatório de Pesquisa aprovado pelo CNPq, não publicado. Recife: UFPE.

COUTINHO, S. G.; LOPES, M. T. 2011. Design para educação: uma possível contribuição para o ensino fundamental brasileiro. In: BRAGA, M. C. (Org.), O Papel social do design gráfico: história, conceitos \& atuação profissional. São Paulo: Editora SENAC, p.137-162.

COUTINHO, S. G.; FREIRE, V. E. C. 2007. Design para educação: uma avaliação do uso da imagem nos livros infantis de Língua Portuguesa. In: ROCHA, C. (Org.), Arte: limites e contaminações - Anais do $15^{\circ}$ Encontro Nacional da ANPAP (2006). Salvador: ANPAP/UNIFACS, vol. II, pp.245-254.

DEMARCHI, A. P. P.; REGO, R. 2002. A. Marketing e Design: Ferramentas de Integração Organizacional nas Empresas. Anais do $5^{\circ}$ Congresso Brasileiro de Pesquisa \& Desenvolvimento em Design. Rio de Janeiro.

DONDIS, A. D. 1997. Sintaxe da linguagem visual. 2ed. São Paulo: Martins Fontes.

FREITAS, R. F. 2011. Análise de Metodologias em Design: a informação tratada por diferentes olhares (mimeo). Recife: Pós-Graduação em Design da UFPE.

GOLDSMITH, E. 1984. Research into illustration: an approach and a review. Cambridge: Cambridge University Press.

PENN, G. 2008. Análise de imagens paradas. In: BAUER, M. W. e GASKEL, G. (Eds.) Pesquisa qualitativa com texto: imagem e som: um manual prático. Tradução de Pedrinho A. Guareschi. -7 ed. Petrópolis: Vozes.

PINE, J. II; GILMORE, J. H. 1998. Welcome to the experience economy. Busines Review, Harvard, v. 76, July-August.

REDISH, J. 2000. What's information design? Technical Comunication Journal. Disponível em: <http://dwheelersite.com/PDFs/Articles\%20for\%20Reading\%20List/Redish\%20What\%20ls\%20l nformation \%20Design.pdf>. Acesso em julho de 2012.

SCHRIVER, K. 1997. Dynamics in Document Design: creating texts for readers. Nova York: Wiley \& Sons.

SLESS, D. 2005. Designing for safety: a guide to my presentation. Disponível em: <http://www.buksa.com/MediaGallery/Documents/Halifax/2005/H5---006---Sless.pdf>. Acesso em julho de 2012.

SIMLINGER, P. 2007. Information design: core competencies what information designers know and can do. Disponível em: <http://www.iiid.net/PDFs/idxPublication.pdf>. Acesso em julho de 2012. 


\section{Sobre as autoras}

Maria Teresa Lopes, Doutoranda em design da informação pela Universidade Federal de Pernambuco - UFPE, professora substituta de design na UFPE e professora na UNICAP Universidade Católica de Pernambuco.

<teresa.designer@gmail.com>

Solange Galvão Coutinho, doutora, UFPE; Ph.D. pela University of Reading - Typography \& Graphic Communication (1998); Professora da UFPE, desde 1984; Pesquisadora do Centre de Recherche Images, Cultures et Cognitions (CRICC), Paris 1 - Pantheon Sorbonne; Líder do Grupo de Pesquisa em Design da Informação.

<solangecoutinho@globo.com>

Natália Cristina Pereira Barbosa, estudante do bacharelado em Design, UFPE. Bolsista de Iniciação Científica UFPE/CNPq.

< tatinhabarbosa@gmail.com >

[Artigo recebido em dezembro de 2012, aprovado em dezembro de 2012] 